\title{
A One-Step Reverse Transcription-Polymerase Chain Reaction System for the Simultaneous Detection and Identification of Multiple Tospovirus Infections
}

\author{
Hiroyuki Uga and Shinya Tsuda
}

First author: Saitama Prefectural Agriculture and Forestry Research Center, Kuki, Saitama 346-0037, Japan; and second author: Department of Plant Pathology, National Agricultural Research Center, Tsukuba 305-8666, Japan. Accepted for publication 21 October 2004.

\begin{abstract}
Uga, H., and Tsuda, S. 2005. A one-step reverse transcription-polymerase chain reaction system for the simultaneous detection and identification of multiple tospovirus infections. Phytopathology 95:166-171.

A one-step reverse transcription-polymerase chain reaction (RT-PCR) method has been developed for the simultaneous detection and identification of multiple tospoviruses that infect plants. The RT-PCR system is composed of six primers in a single tube: a universal degenerate primer and five virus species-specific primers. Amplifications resulted in an

848-bp PCR product for Watermelon silver mottle virus, 709-bp for Tomato spotted wilt virus, 589-bp for Impatiens necrotic spot virus, 511-bp for Melon yellow spot virus, and a 459-bp amplicon for Iris yellow spot virus. This system enables the simultaneous detection of at least three types of tospovirus infections, in addition to their species identities, from five possible tospoviruses studied, on the basis of their S RNA combinations. This multiplex RT-PCR system was applied to the detection of tospovirus in ornamental crops cultivated in fields and shows potential for epidemiological studies.
\end{abstract}

Tospoviruses, which belong to the family Bunyaviridae, are agriculturally important; they cause severe economic damage to various crops and flowers and are transmitted by thrips in a circulative and propagative manner (7). These viral particles are spherical with a lipid envelope containing the nucleocapsid. The genome consists of three RNA segments, L, M, and S, in which the five open reading frames encode at least six essential proteins (15). Tomato spotted wilt virus (TSWV) is the type species of the genus Tospovirus, which consists of at least 13 species $(2,15,30)$. Field occurrences of tospovirus diseases in Japan are attributed to the five previously reported species: TSWV on chrysanthemum, tomato, and green pepper $(24,28,42)$; Watermelon silver mottle virus (WSMoV) on watermelon and New Zealand spinach $(18,37)$; Melon yellow spot virus (MYSV) on melon and cucumber (20,38); Impatiens necrotic spot virus (INSV) on cineraria, cyclamen, and prairie gentian $(4,11,40)$; and Iris yellow spot virus (IYSV) on prairie gentian and alstroemeria $(5,33)$. Serological diagnostic techniques used for the detection of tospoviruses have mostly been based on enzyme-linked immunosorbent assay (ELISA) using specific polyclonal antiserum against the nucleocapsid, due to the ease of the purification step, in preference to methods that rely on detection of the complete particle with envelope, which require a difficult envelope-particle preparation $(10,14,36,38,40,43)$. Although using ELISA is the established method in the routine diagnosis of plant virus diseases, including tospoviruses, cross-reaction can occur within the same serogroup due to common antigenic determinants on the nucleocapsid (45).

Reverse transcription-polymerase chain reaction (RT-PCR) has been widely used as a highly sensitive and specific detection method for infectious diseases, including plant viruses. A PCR method using a common primer pair to amplify conserved regions of the family Potyviridae has succeeded in the detection of 17

Corresponding author: S. Tsuda; E-mail address: shinyat@affrc.go.jp

DOI: 10.1094/PHYTO-95-0166

(c) 2005 The American Phytopathological Society species. This, however, does not discriminate between individual species (8). In the literature, reports using PCR to identify the species of virus within a genus describe the use of degenerate primers in amplification followed by the treatment of PCR products with restriction endonuclease cleavage $(27,34)$. Recently, multiplex RT-PCR methods have been reported employing combinations of gene-specific primer pairs to simultaneously detect infection by multiple species of a virus in a single plant $(1,6,9,12$, 13,17,19,26,31). A new approach adopting a two-step RT-PCR using both a degenerate primer and sequence-specific primers was recently reported for the detection and identification of potyviruses and ilarviruses; this technique does not require any postPCR steps, such as restriction endonuclease treatment $(32,35)$.

RT-PCR using a gene-specific primer pair has also been applied to the detection of tospoviruses in plants and thrips vectors as a diagnostic technique $(7,30,41)$. In addition, the employment of degenerate primers in RT-PCR has enabled the identification of individual tospovirus species $(2,3,33)$. However, these methods require a number of additional steps post-PCR, which add to the complexity and the overall length of the procedure. We herein report a one-step RT-PCR system for the simultaneous detection and identification of five different tospovirus species. A single universal degenerate primer corresponding to the 3 '-noncoding region conserved among tospoviruses is used with five speciesspecific primers against the different viral S RNAs. This singletube procedure might be suitable as a diagnostic tool in crop cultivation.

\section{MATERIALS AND METHODS}

Viruses and RNA preparations. TSWV was isolated from green pepper (42), IYSV from onion (44), MYSV from melon (20), WSMoV from watermelon (18), and INSV from verbena (22). These samples were all collected in Japan. Virus species were identified by serology using species-specific antibodies or sequencing of the nucleocapsid protein gene encoded on the $\mathrm{S}$ RNA and were used as standard virus samples for the establish- 
ment of the RT-PCR system. Each virus was propagated once with Nicotiana benthamiana and then the infected systemic leaves were used for RNA extraction, also in cases for co-inoculations with several tospoviruses. Total RNAs were extracted using an RNeasy Plant Mini Kit (Qiagen, Hilden, Germany) following the manufacturer's instructions.

Design of a universal degenerate primer and species-specific primers. Primers for RT-PCR were designed from the nucleotide sequences of the nucleocapsid protein $(N)$ gene and the $3^{\prime}$ untranslated sequences of the S RNA. The following nucleotide sequence data were obtained from the databases of DDBJ/ EMBL/GenBank: 18 isolates of TSWV (AB088385, AF020659, AF020660, AJ296598, AJ296599, AJ296600, AJ296601, AJ296603, AJ297607, AJ297608, AJ297610, AJ418777, AJ418778, AJ418779, AJ418780, AJ418781, D13926, and L20953); three isolates of IYSV (AF001387, AF067070, and AF271219); three isolates of MYSV (AB024332, AB038343, and $\mathrm{AB} 076250)$; two isolates of WSMoV (U78734 and X78556); and four isolates of INSV (D00914, L20885, L20886, and X66972). Sequence alignments of these isolates were performed using the CLUSTAL W program. A universal degenerate primer for the first-strand cDNA synthesis, which also functions as the reverse primer for the PCR step, was designed from the conserved region-a 15-nucleotide sequence at the $3^{\prime}$ terminus of the $S$ RNA-from 21 isolates of the five tospoviruses: TSWV, IYSV, MYSV, WSMoV, and INSV (Table 1). Three guanosines were joined to the $5^{\prime}$-tail of the degenerate primer to establish a melting temperature $\left(T_{m}\right)$ in common with species-specific primers. Each species-specific primer was designed within the conserved region of the S RNA sequences of each virus species using the GENETYX-WIN program version 4.1 (Software Development, Tokyo, Japan). Sequences with similar $T_{m}$ values were sought for each of the species-specific primers (Table 1). For RT-PCR, primer combinations were chosen to generate PCR products of different sizes for each virus that would be discernible by agarose gel electrophoresis. Three primer sets, consisting of one universal degenerate primer and five species-specific primers, were synthesized and tested in order to detect and identify five tospoviruses (Table 2).

RT-PCR. RT-PCR was carried out using the One-Step RNA PCR Kit (AMV) (TAKARA, Shiga, Japan) in a 0.2-ml micro test tube following the manufacturer's instruction. One microliter of total RNA was extracted with the kit as described previously and added to the tube containing the reaction mixture, including the primers. The final primer concentrations used were $2 \mu \mathrm{M}$ for the degenerate primer and $0.2 \mu \mathrm{M}$ for each species-specific primer, as

TABLE 1. Oligonucleotide primer sequences for multiplex reverse transcription-polymerase chain reaction

\begin{tabular}{llcc}
\hline Primer $^{\mathrm{a}}$ & \multicolumn{1}{c}{ Sequence $^{\mathrm{b}}$} & $\begin{array}{c}\text { Length } \\
(\mathrm{mer})\end{array}$ & $\begin{array}{c}T_{m} \\
\left({ }^{\circ} \mathrm{C}\right)\end{array}$ \\
\hline WSMoV-848 & 5'-ATCACCATAATCATCCACAG-3' $^{\prime}$ & 20 & 51 \\
WSMoV-524 & 5'-TCCAATACATAACATCATCC-3' $^{\prime}$ & 20 & 49 \\
TSWV-709 & 5'-GTGTCATACTTCTTTGGGTC-3' & 20 & 53 \\
INSV-589 & 5'-CCCAAGACACAGGATTTCA-3' & 19 & 53 \\
MYSV-834 & 5'-TCTCACCCATTCCATCAAC-3' & 19 & 53 \\
MYSV-511 & 5'-TCTCAAAGCTGTCATGTCAAAC-3' & 22 & 53 \\
MYSV-433 & 5'-TGCTTTTCTTCCTCATTCTC-3' & 20 & 51 \\
IYSV-837 & 5'-GTTTAGAAGACTCACCAATG-3' & 20 & 51 \\
IYSV-459 & 5'-ACCAGAGGAAGCCCGCAG-3' & 18 & 59 \\
TOS-R15 & 5'-GGGAGAGCAATYGWGKYR-3' & 18 & 55 \\
\hline
\end{tabular}

a WSMoV, Watermelon silver mottle virus; TSWV, Tomato spotted wilt virus; INSV, Impatiens necrotic spot virus; MYSV, Melon yellow spot virus; and IYSV, Iris yellow spot virus. TOS-R15 primer is the reverse degenerate primer common to the five tospoviruses. The others are species-specific primers designed from viral S RNA sequences. The number following primer names indicates the amplified fragment size.

${ }^{\mathrm{b}}$ Nucleotides at degenerate positions are represented by a single letter code: $\mathrm{Y}$, $\mathrm{C}$, and $\mathrm{T} ; \mathrm{W}, \mathrm{A}$, and $\mathrm{T} ; \mathrm{K}, \mathrm{G}$, and $\mathrm{T}$; and $\mathrm{R}, \mathrm{A}$, and $\mathrm{G}$. shown in Table 2. The RT-PCR was performed at $50^{\circ} \mathrm{C}$ for $30 \mathrm{~min}$ for 1 cycle, $94^{\circ} \mathrm{C}$ for $2 \mathrm{~min}$ for 1 cycle and $94^{\circ} \mathrm{C}$ for $30 \mathrm{~s}, 54^{\circ} \mathrm{C}$ for $30 \mathrm{~s}$, and $72^{\circ} \mathrm{C}$ for $1 \mathrm{~min}$ for 35 cycles. The amplified cDNA was separated by electrophoresis using $1.5 \%$ agarose gels.

Sequencing of amplified fragments. Amplified RT-PCR products were directly sequenced to confirm their origins from the target virus species. An ABI Prism 310 DNA Sequencer with an ABI Prism BigDye Terminator Cycle Sequencing Ready Reaction Kit (Perkin-Elmer, Foster City, CA) was used in accordance with the manufacturer's instructions.

Application for crops infected in fields. The field performance of this system was assessed using symptom-free and naturally infected plants (showing characteristic symptoms of tospovirus infection) from the following species: Dimorphotheca sinuate (cape marigold), Eucharis grandiflora (amazon lily), Eustoma grandiflorum (prairie gentian), Felicia amelloides (blue daisy), Cyclamen persicum (cyclamen), and Kalanchoe blossfeldiana (kalanchoe). All plants were cultivated in different fields in the Saitama and Yamanashi Prefectures, Japan. The method used for total RNA extraction was as described previously.

\section{RESULTS}

Specificity of primer mix in RT-PCR. Each of the three primer sets was composed of one universal degenerate primer (TOS-R15) and five species-specific primers (Table 2). The abilities of these to identify the tospoviruses WSMoV, TSWV, INSV, MYSV, and IYSV were assessed. When the total RNAs extracted from plants individually infected with WSMoV, TSWV, INSV, MYSV, or IYSV were employed with primer set II, cDNA fragment sizes of $848,709,589,511$, or $459 \mathrm{bp}$, respectively, were amplified, all without nonspecific amplifications. The molecular sizes of each fragment amplified were in accordance with the known cDNA sequence. No cDNA fragments were obtained from healthy $N$. benthamiana (Fig. 1B). Primer sets I and III amplified cDNA fragments to comparable levels to primer set II. However, some nonspecific amplifications appeared in IYSV with primer set I, and in MYSV and IYSV with primer set III (Fig. 1A and $\mathrm{C}$ ). These were presumably due to priming at similar nontarget sequences of viral origin, as no fragments were seen in healthy controls. On the basis of these observations, primer set II was chosen for the following experiments. The sequences from individual cDNA fragments for five tospoviruses amplified by primer set II were identical to those of the original viral S RNA (data not shown).

Sensitivity of the one-step RT-PCR system in single tospovirus infection. The detection limits of primer set II in single tospovirus infection were determined by making 10 -fold serial dilutions of virus-infected total RNAs thinned with RNA extracts from healthy plants. TSWV-, MYSV-, and IYSV-specific fragments were visible up to $10^{-4}$ dilutions, whereas the INSV-specific product was detected up to a $10^{-5}$ dilution (data not shown).

TABLE 2. Three primer sets used in this study

\begin{tabular}{llll}
\hline & \multicolumn{3}{c}{ Name of primer set } \\
\cline { 2 - 4 } Primer $^{\mathrm{a}}$ & \multicolumn{1}{c}{ I } & \multicolumn{1}{c}{ II } & \multicolumn{1}{c}{ III } \\
\hline Species-specific & IYSV-837 & WSMoV-848 & MYSV-834 \\
& TSWV-709 & TSWV-709 & TSWV-709 \\
& INSV-589 & INSV-589 & INSV-589 \\
& WSMoV-524 & MYSV-511 & WSMoV-524 \\
Universal & MYSV-433 & IYSV-459 & IYSV-459 \\
\hline
\end{tabular}

${ }^{a}$ WSMoV, Watermelon silver mottle virus; TSWV, Tomato spotted wilt virus; INSV, Impatiens necrotic spot virus; MYSV, Melon yellow spot virus; and IYSV, Iris yellow spot virus. TOS-R15 primer is the reverse degenerate primer common to the five tospoviruses. Forward primers are speciesspecific. The number following primer names indicates the amplified fragment size. 
Simultaneous detection of various combinations of viral RNAs from five tospovirus infections. Because multiple infections of TSWV and INSV have been reported in Japan in Eustoma grandiflorum $(4,25)$, Impatiens walleriana $(23,39)$, Senecio hybridus (21,39), and Verbena hybrida (16,23), amplification using primer set II was tested in a simulation of dual viral infection. Considering all five viruses, the 10 possible pairwise combinations were tested. Total RNA extracts from plants infected with different tospoviruses were mixed equally and subjected to one- step RT-PCR (Fig. 2A). Moreover, to test the appropriateness of the assay for multiple infections by more than two species of tospoviruses, 16 possible combinations were tested with mixtures from five species of total RNAs extracted from infected plants (Fig. 2B). In all of the combinations tested, five virus-specific cDNA fragments could be successfully detected in a single reaction without a reduction of products compared with that of single virus RNA samples in the one-step RT-PCR using primer set II. These results suggest that the one-step RT-PCR potentially would
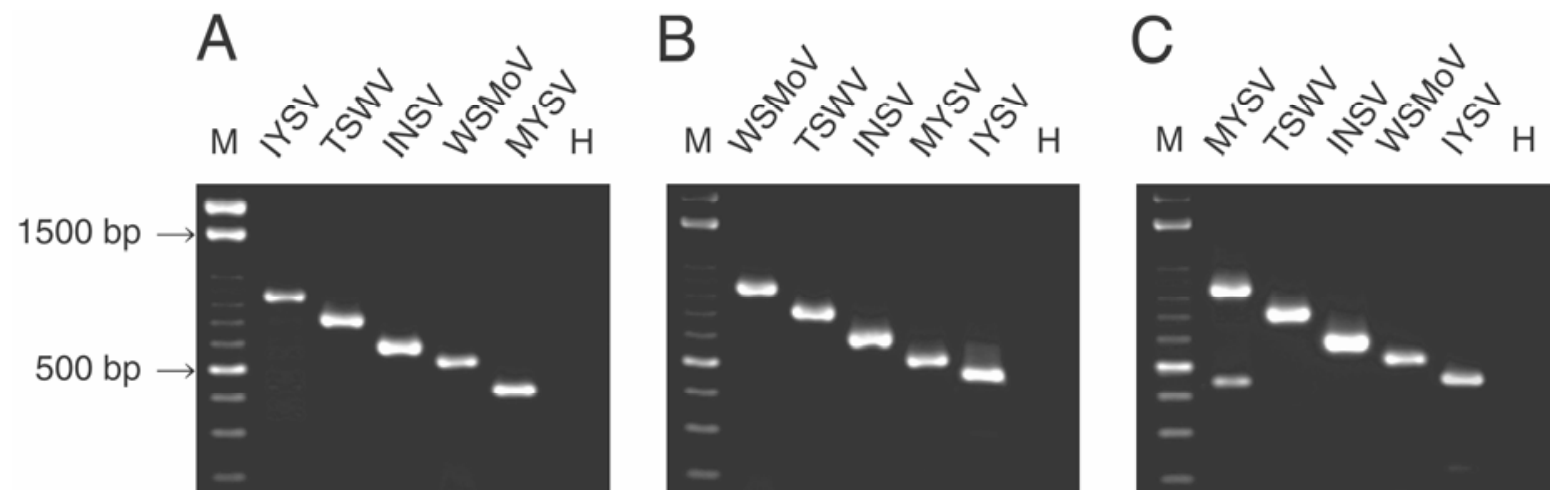

Fig. 1. Detection of five tospoviruses by one-step reverse transcription-polymerase chain reaction (RT-PCR) employing three mixed primer sets consisting of one degenerate primer and five species-specific primers. A, primer set I; B, primer set II; and C, primer set III (Table 2). RT-PCR was performed using total RNAs extracted from plants infected with five different strains of tospoviruses. Virus-specific amplification products corresponded to A, 837 bp for Iris yellow spot virus (IYSV), 709 bp for Tomato spotted wilt virus (TSWV), 589 bp for Impatiens necrotic spot virus (INSV), 524 bp for Watermelon silver mottle virus (WSMoV), and $433 \mathrm{bp}$ for Melon yellow spot virus (MYSV); B, $848 \mathrm{bp}$ for WSMoV, $709 \mathrm{bp}$ for TSWV, $589 \mathrm{bp}$ for INSV, $511 \mathrm{bp}$ for MYSV, and $459 \mathrm{bp}$ for IYSV; and C, $834 \mathrm{bp}$ for MYSV, 709 bp for TSWV, 589 bp for INSV, 524 bp for WSMoV, and 459 bp for IYSV. Lane H, Total RNA extracted from healthy plants of Nicotiana benthamiana. Lane M, 100-bp ladder markers (Toyobo, Osaka, Japan).

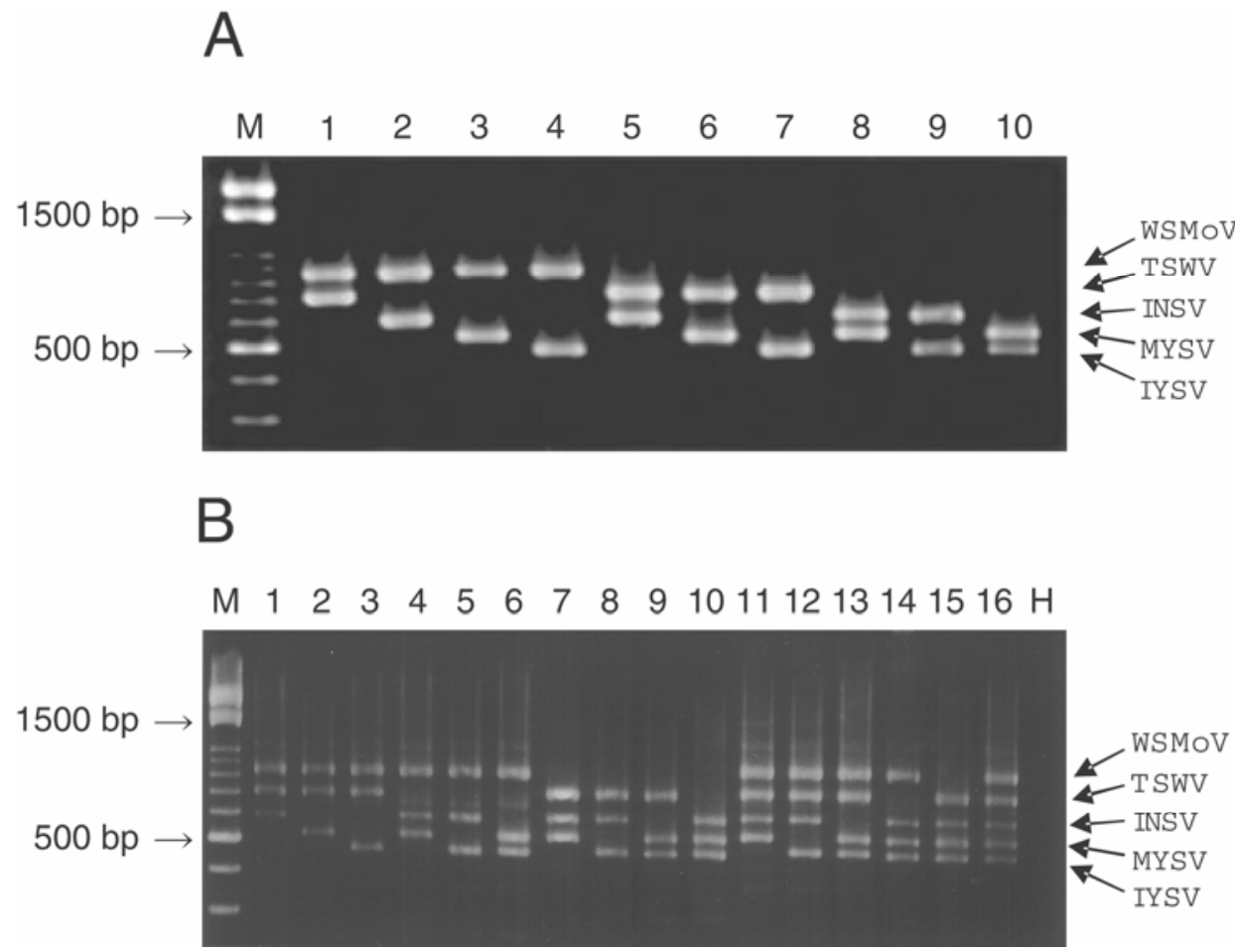

Fig. 2. Simultaneous detection of all possible combinations of five tospoviruses by one-step reverse transcription-polymerase chain reaction (RT-PCR) using primer set II, comprising one degenerate primer and five species-specific primers (Table 2). A, RT-PCR was performed using a mixture of two species of total RNAs extracted from viral infected plants with Watermelon silver mottle virus (WSMoV) and Tomato spotted wilt virus (TSWV) (lane 1); WSMoV and Impatiens necrotic spot virus (INSV) (lane 2); WSMoV and Melon yellow spot virus (MYSV) (lane 3); WSMoV and Iris yellow spot virus (IYSV) (lane 4); TSWV and INSV (lane 5); TSWV and MYSV (lane 6); TSWV and IYSV (lane 7); INSV and MYSV (lane 8); INSV and IYSV (lane 9); and MYSV and IYSV (lane 10). B, RT-PCR for all possible combinations of a mixture from five species of total RNAs extracted from viral infected plants with WSMoV, TSWV, and INSV (lane 1); WSMoV, TSWV, and MYSV (lane 2); WSMoV, TSWV, and IYSV (lane 3); WSMoV, INSV, and MYSV (lane 4); WSMoV, INSV, and IYSV (lane 5); WSMoV, MYSV, and IYSV (lane 6); TSWV, INSV, and MYSV (lane 7); TSWV, INSV, and IYSV (lane 8); TSWV, MYSV, and IYSV (lane 9); INSV, MYSV, and IYSV (lane 10); WSMoV, TSWV, INSV, and MYSV (lane 11); WSMoV, TSWV, INSV, and IYSV (lane 12); WSMoV, TSWV, MYSV, and IYSV (lane 13); WSMoV, INSV, MYSV, and IYSV (lane 14); TSWV, INSV, MYSV, and IYSV (lane 15); and WSMoV, TSWV, INSV, MYSV, and IYSV (lane 16). Arrows indicate the virus-specific amplification products corresponding to $848 \mathrm{bp}$ for WSMoV, 709 bp for TSWV, $589 \mathrm{bp}$ for INSV, 511 bp for MYSV, and 459 bp for IYSV. Lane H, Total RNA extracted from healthy plants of Nicotiana benthamiana. Lane M, 100-bp ladder markers (Toyobo, Osaka, Japan). 
be able to detect and identify five different tospoviruses simultaneously.

Sensitivities of simultaneous detection of two viruses by competitive RT-PCR. We tested the double-detection system for different quantities of the two tospoviral RNAs, as viral titer may differ in co-infected plants. Each of the total RNAs, separately extracted from TSWV- or INSV-infected plants, was first adjusted to $200 \mathrm{ng} / \mu \mathrm{l}$. Tenfold serial dilutions of one virus-infected RNA of the order $\times 10^{0}$ to $\times 10^{-3}$ were diluted with total RNA extracts from healthy plants and added to aliquots of an equal volume of another virus-infected RNA extract that had been prepared similarly. These mixtures were tested, and each of the cDNA fragments of TSWV (709 bp) and INSV (589 bp) was amplified up to $10^{-2}$ dilution (Fig. 3A). When viral proportions were unequal, the amount of amplified product decreased with the amount of starting virus. In MYSV and IYSV, the detection limit was investigated using the same method, because all 15 nucleotides at the $3^{\prime}$ terminus of both viral S RNAs that could be recognized by a universal degenerate primer were identical, showing the possibility that a decrease in PCR sensitivity was due to competition between RNA templates for the degenerate primer. In the mixture of MYSV and IYSV, each of the cDNA fragments of MYSV (511 bp) and IYSV (459 bp) was amplified only up to $10^{-1}$ dilution, as shown in Figure 3B.

Simultaneous detections for multiply-infected plants that were mechanically co-inoculated with combinations of several tospoviruses. As described previously, double infections of TSWV and INSV have been reported in Japan $(4,16,21,23,25,39)$. However, there may be triple or higher order co-infected crops in fields. To confirm that the system would be adaptable for such cases, multiply-infected plants, $N$. benthamiana or prairie gentian, were prepared by mechanical co-inoculation of several tospovirus combinations using TSWV, IYSV, or INSV (Fig. 4). All of the systemic leaves of plants inoculated resulted in specific cDNA fragments being amplified in this system, including triple infections (Fig. 4, lanes 4 and 8). Taken together with the result described in Figure 2B, the one-step RT-PCR system demonstrated that it is capable of simultaneously detecting and identifying five tospovirus infections, with at least three virus infections in one reaction.

Field trial for virus detection in naturally infected plants. Six species of plants cultivated in different fields that showed necrotic symptoms characteristic of tospovirus infection were tested using the one-step RT-PCR system with primer set II (Fig. 5). Fragments of $709 \mathrm{bp}$, indicative of TSWV cDNA, were amplified from three diseased cape marigold plants, five blue daisy plants, and two kalanchoe plants (Fig. 5, lanes 1, 4, and 6). The 589-bp PCR product, indicative of INSV cDNA, was amplified from two cyclamen plants (Fig. 5, lane 5), and the 459-bp fragment, indicative of IYSV cDNA, was amplified from two amazon lily plants and three prairie gentian plants (Fig. 5, lanes 2

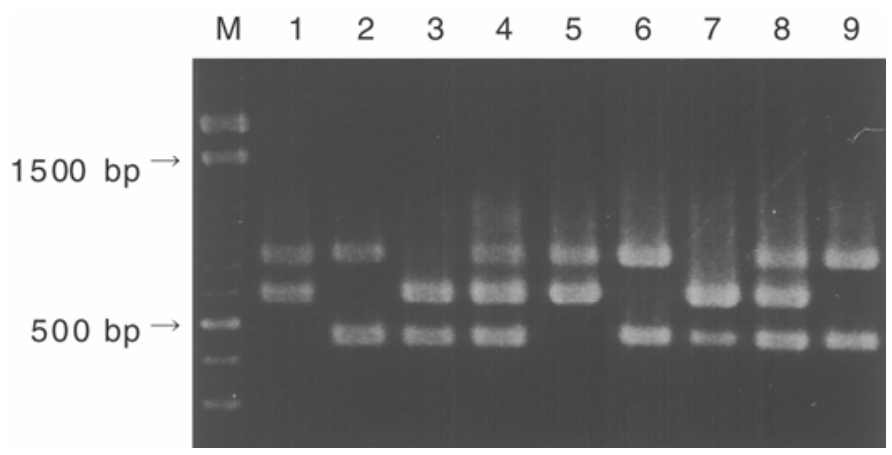

Fig. 4. Simultaneous detection for tospoviruses by one-step reverse transcription-polymerase chain reaction (RT-PCR) using primer set II from multiply infected plants that were mechanically inoculated with several tospoviruses at one time. RT-PCR was performed using the total RNAs extracted from Nicotiana benthamiana (lanes 1 to 8) and prairie gentian (lane 9) infected with Tomato spotted wilt virus (TSWV) and Impatiens necrotic spot virus (INSV) (lanes 1 and 5); TSWV and Iris yellow spot virus (IYSV) (lanes 2, 6, and 9); INSV and IYSV (lanes 3 and 7); and TSWV, INSV, and IYSV (lanes 4 and 8). Lane M, 100-bp ladder markers (Toyobo, Osaka, Japan).

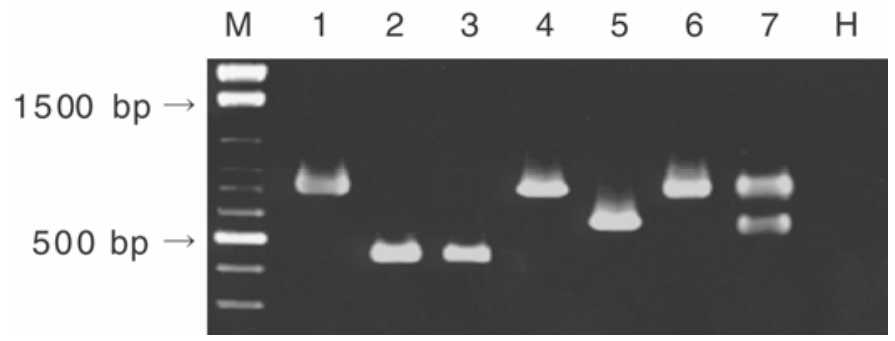

Fig. 5. Detection of tospoviruses from field samples by one-step reverse transcription-polymerase chain reaction (RT-PCR) using primer set II. RTPCR was performed using the total RNAs extracted from cape marigold (lane 1), amazon lily (lane 2), prairie gentian (lane 3), blue daisy (lane 4), cyclamen (lanes 5 and 7), and kalanchoe (lane 6). Lane H, Total RNA extracted from healthy plants of Nicotiana benthamiana. Lane M, 100-bp ladder markers (Toyobo, Osaka, Japan).
A

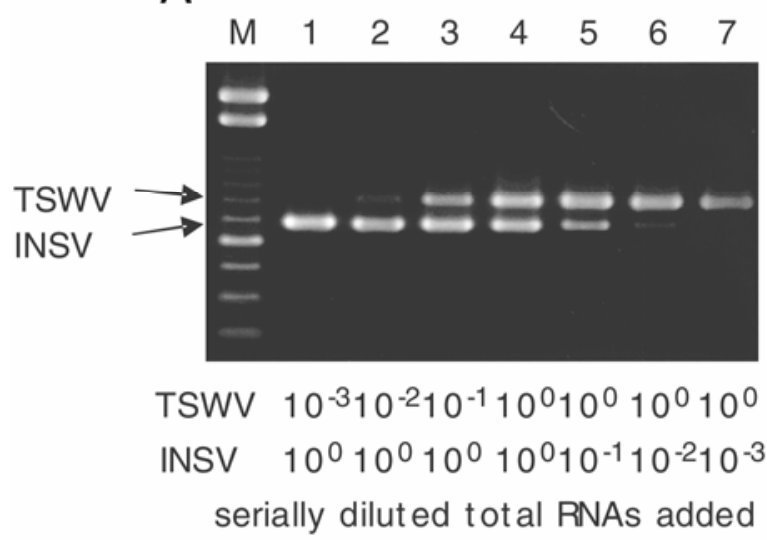

B

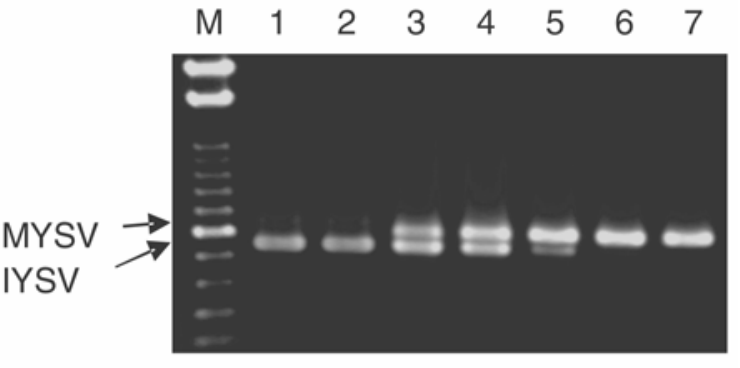

MYSV $10^{-3} 10^{-2} 10^{-1} 10^{0} 10^{0} 10^{0} 10^{0}$

IYSV $10^{0} 10^{0} 10^{0} 10^{0} 10^{-1} 10^{-2} 10^{-3}$

serially diluted total RNAs added

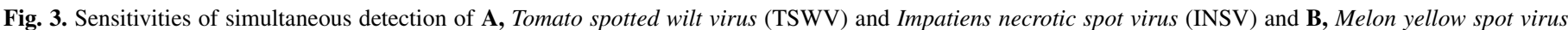

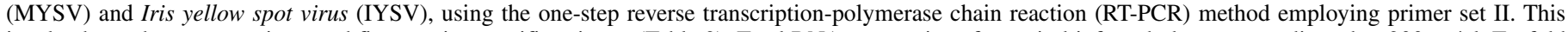

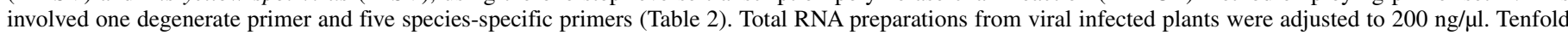

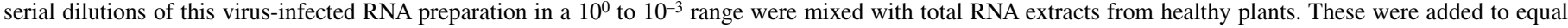

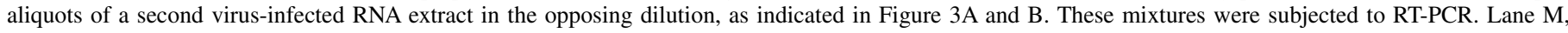
100-bp ladder markers (Toyobo, Osaka, Japan). 
and 3). These infected plants were presumed to have a single infection of tospovirus, but still a remaining possibility is that there could be a mixed infection with a primary virus that is present in a much higher proportion than the others. A double infection by TSWV and INSV was seen in one cyclamen plant (Fig. 5, lane 7), showing the adaptability of this technique for use as a field assay of tospovirus disease. Amplification of viral cDNA was not seen from symptom-free plants. When sap from each of the fieldgrown plants was tested by double-antibody sandwich-ELISA to confirm the results from the RT-PCR, viruses separately identified with both techniques completely corresponded (data not shown). To confirm the identities of the RT-PCR products, amplified products were directly sequenced using a primer specific to the respective viruses. The RT-PCR product sequences were identical or showed close identity, having $98 \%$ or higher identity in each species, compared with that of the published sequences of the $S$ RNA region (data not shown).

\section{DISCUSSION}

We have described a one-step RT-PCR system that can simultaneously detect and identify multiple tospoviruses. The system is composed of a universal reverse degenerate primer and five virus species-specific forward primers. A number of rapid tospovirus detection systems based on RT-PCR employing degenerate primers targeting conserved sequences of various species within a group have been reported $(2,3,33)$. However, these methods require the treatment of amplified PCR products with restriction endonucleases to identify the virus species. An advantage of the one-step RT-PCR system is its ability to detect and discriminate individual tospoviruses and co-infections without the need for restriction endonuclease treatment or serological methods. In addition, we found that the limit of sensitivity when detecting a plural viral RNA infection was comparable to that of a single tospovirus detection using single gene-specific primer pairs (29). To our knowledge, this is the first report of a multiplex one-step RT-PCR detection system for tospoviruses.

Recently, multiplex RT-PCR methods have been reported describing the simultaneous detection and identification of two or more viruses. Most of these methods employ a set of primer pairs, where both forward and reverse primers are specific to the gene sequences of the target virus $(1,9,13,17,19,26,31)$. Limitations on the number of virus species that can be detected simultaneously are attributed to the interferences that occur in PCR amplifications at high oligonucleotide and primer concentrations $(1,32)$. As far as we are aware, there have been only two reports of multiplex RT-PCR methods for plant virus detection using a cocktail of primers and employing a universal degenerate primer that does not require the use of restriction endonuclease treatments: one method was developed to detect three ilarviruses from triple-infected stone fruit trees (35) and the other was used to distinguish strains of Potato virus $Y$ (32). Among the critical parameters requiring configuration for multiplex RT-PCR, the yield and quality of total RNA extracted are the most significant $(1,6,26,31,32)$. If the number of misannealing reactions is reduced and the generation of potentially competing erroneous PCR products is suppressed, both viral-specific and common primers might function effectively in detecting viral templates $(1,32)$. As illustrated by the MYSV and IYSV combination in Figure 3B, the detection end point for two viral RNAs set at equivalent concentrations was less than when only one virus was present. The universal degenerate primer would presumably compete for the two viral templates, thus lowering the end point of detection.

The three primer sets employed in the multiplex RT-PCRs displayed some variation. Nonspecific reactions were seen for two primer sets (gels A and C) but not for primer set II (gel B), as shown in Figure 1. Our findings suggest that several sequence designs for primers must be rigorously tested when developing a multiplex PCR system and, in particular, when employing degenerate primers, taking into consideration primer length, primer $\mathrm{G}+\mathrm{C}$ content, and primer $T_{m}$. In the multiplex RT-PCR system for the ilarvirus, the universal degenerate primer employed was such that the last eight bases at the $3^{\prime}$ terminus of the viral RNA sequences were identical in all three viruses tested, whereas the remaining five nucleotides at the $5^{\prime}$ terminus varied (35). A similar situation for the system described in this report has been seen in the TOS-R15 primer, since the last eight bases at the $3^{\prime}$ terminus of the primer are common to the five tospoviruses used, and the remaining five bases at the $5^{\prime}$ terminus are different but include two identical bases ( $\mathrm{G}$ in each), additionally, in the viruses (Table 1). The base-sequence match at the $3^{\prime}$ terminus is more important than that of the $5^{\prime}$ terminus (35), which is a critical feature in the design of the PCR primers.

Serological methods are useful techniques in primary diagnostic assays of tospovirus infections $(10,14,36,43)$; however, specific antisera must be prepared for each species. Using our method, not only single infections but also multiple infections were detected in a screen against five tospoviruses from 18 infected cultivated plants of six different species showing typical necrotic symptoms, which were harvested in crop fields, showing the possibility of five tospoviruses being simultaneously detected. This half-day procedure, which can be performed in a single test, would be useful in field-based epidemiological studies. In addition, with the development of new forward primers based on other tospovirus sequences, this system has the potential to be used in the identification of additional variants of tospovirus other than the five species used in this study. It is hoped that application of this method will be extended to other virus types.

\section{ACKNOWLEDGMENTS}

We thank T. Kawano (Japanese Plant Protection Association) for providing tospovirus-diseased ornamental crops cultivated in fields in Japan.

\section{LITERATURE CITED}

1. Bariana, H. S., Shannon, A. L., Chu, P. W. G., and Waterhouse, P. M. 1994. Detection of five seedborne legume viruses in one sensitive multiplex polymerase chain reaction test. Phytopathology 84:1201-1205.

2. Chu, F. H., Chao, C. H., Chung, M. H., Chen, C. C., and Yeh, S. D. 2001. Completion of the genome sequence of Watermelon silver mottle virus and utilization of degenerate primers for detecting tospoviruses in five serogroups. Phytopathology 91:361-368.

3. Dewey, R. A., Semorile, L. C., and Grau, O. 1996. Detection of tospovirus species by RT-PCR of the N-gene and restriction enzyme digestions of the products. J. Virol. Methods 56:19-26.

4. Doi, M., and Kato, K. 2002. New virus diseases in lisianthus caused by Iris yellow spot virus (IYSV) and Impatiens necrotic spot virus (INSV). (Abstract in Japanese.) Jpn. J. Phytopathol. 68:231.

5. Doi, M., Zen, S., Okuda, M., Nakamura, H., Kato, K., and Hanada, K. 2003. Leaf necrosis disease of lisianthus (Eustoma grandiflorum) caused by Iris yellow spot virus. (In Japanese with English summary.) Jpn. J. Phytopathol. 69:181-188.

6. Dovas, C. I., Katis, N. I., and Avgelis, A. D. 2002. Multiplex detection of criniviruses associated with epidemics of a yellowing disease of tomato in Greece. Plant Dis. 86:1345-1349.

7. German, T. L., Ullman, D. E., and Moyer, J. W. 1992. Tospoviruses: Diagnosis, molecular biology, phylogeny, and vector relationship. Annu. Rev. Phytopathol. 30:315-348.

8. Gibbs, A., and Mackenzie, A. 1997. A primer pair for amplifying part of the genome of all potyvirids by RT-PCR. J. Virol. Methods 63:9-16.

9. Gitton, F., Diao, A., Ducrot, O., Antoniw, J. F., Adams, M. J., and Maraite, H. 1999. A two-step multiplex RT-PCR method for simultaneous detection of Soil-borne wheat mosaic virus and Wheat spindle streak mosaic virus from France. Plant Pathol. 48:635-641.

10. Gonsalves, D., and Trujillo, E. E. 1986. Tomato spotted wilt virus in papaya and detection of the virus by ELISA. Plant Dis. 70:501-506.

11. Goto, T., Sazarashi, H., Nozawa, H., Nakayama, K., and Natsuaki, T. 2001. Necrotic spot of cyclamen and exacum caused by Impatiens necrotic spot virus (INSV). (Abstract in Japanese.) Jpn. J. Phytopathol. $67: 173$. 
12. Grieco, F., and Gallitelli, D. 1999. Multiplex reverse transcriptase-polymerase chain reaction applied to virus detection in globe artichoke. J. Phytopathol. 147:183-185.

13. Hauser, S., Weber, C., Vetter, G., Stevens, M., Beuve, M., and Lemaire, O. 2000. Improved detection and differentiation of poleroviruses infecting beet or rape by multiplex RT-PCR. J. Virol. Methods 89:11-21.

14. Hsu, H. T., Ueng, P. P., Chu, F. H., Ye, Z., and Yeh, S. D. 2000. Serological and molecular characterization of a high temperature-recovered virus belonging to tospovirus serogroup IV. J. Gen. Plant Pathol. 66:167175.

15. Hull, R. 2002. Matthews' Plant Virology. 4th ed. Academic Press, San Diego.

16. Iriyama, K., Hirata, H., Oshima, K., and Namba, S. 1999. Impatiens necrotic spot virus detected in Verbena hybrida. (Abstract in Japanese.) Jpn. J. Phytopathol. 65:379.

17. Ito, T., Ieki, H., and Ozaki, K. 2002. Simultaneous detection of six citrus viroids and Apple stem grooving virus from citrus plants by multiplex reverse transcription polymerase chain reaction. J. Virol. Methods 106:235239.

18. Iwaki, M., Honda, Y., Hanada, K., Tochihara, H., Yonaha, T., Hokama, K., and Yokoyama, T. 1984. Silver mottle disease of watermelon caused by Tomato spotted wilt virus. Plant Dis. 68:1006-1008.

19. James, D. 1999. A simple and reliable protocol for the detection of Apple stem grooving virus by RT-PCR and in a multiplex PCR assay. J. Virol. Methods 83:1-9.

20. Kato, K., Hanada, K., and Kameya-Iwaki, M. 1999. Transmission mode, host range and electron microscopy of a pathogen causing a new disease of melon (Cucumis melo) in Japan. Ann. Phytopathol. Soc. Jpn. 65:624627.

21. Kawano, T., Hoshi, H., Takahashi, K., Horie, H., and Takahashi, Y. 1998. Necrotic disease of cineraria, marigold and eggplant caused by Tomato spotted wilt virus. (Abstract in Japanese.) Jpn. J. Phytopathol. 64:597598.

22. Kawano, T., Nagano, H., Takahashi, K., Takahashi, Y., Omura, T., and Tsuda, S. 2002. Purification for nucleocapsids of Impatiens necrotic spot virus (INSV) isolated in Japan. (Abstract in Japanese.) Jpn. J. Phytopathol. 68:235

23. Kawano, T., Takahashi, K., Takahashi, Y., Tairako, K., Tsukamoto, S., Kobayashi, K., and Honda, Y. 1999. Spotted wilt disease of verbena, Madagascar periwinkle and impatiens caused by Tomato spotted wilt virus. (Abstract in Japanese.) Jpn. J. Phytopathol. 65:651.

24. Kobatake, H., Osaki, T., Yoshioka, A., and Inouye, T. 1976. Spotted wilt disease of tomatoes in Japan. (In Japanese with English summary.) Ann. Phytopathol. Soc. Jpn. 42:287-294.

25. Kuroda, T., Katsube, K., and Suzuki, K. 1999. Spotted wilt disease of prairie gentian (Eustoma grandiflorum (Ref.) Shinn.) caused by Tomato spotted wilt virus (TSWV). (In Japanese with English summary.) Ann. Phytopathol. Soc. Jpn. 65:490-493.

26. Kuroda, T., Urushibara, S., Takeda, I., and Nakatani, F. 2002. Multiplex reverse transcription polymerase chain reaction for simultaneous detection of viruses in gentian. J. Gen. Plant Pathol. 68:169-172.

27. Langeveld, S. A., Dore, J.-M., Memelink, J., Derks, A. F. L. M., van der Vlugt, C. I. M., Asjes, C. J., and Bol, J. F. 1991. Identification of potyviruses using the polymerase chain reaction with degenerate primers. J. Gen. Virol. 72:1531-1541.

28. Matsuura, S., Hoshino, S., Hayashi, H., Kohguchi, T., Hagiwara, K., and Omura, T. 2002. Effects of latent infection of stock plants and abundance of thrips on the occurrence of Tomato spotted wilt virus in chrysanthemum fields. J. Gen. Plant Pathol. 68:99-102.

29. Mumford, R. A., Barker, I., and Wood, K. R. 1994. The detection of
Tomato spotted wilt virus using the polymerase chain reaction. J. Virol Methods 46:303-311.

30. Mumford, R. A., Barker, I., and Wood, K. R. 1996. The biology of the tospoviruses. Ann. Appl. Biol. 128:159-183.

31. Nassuth, A., Pollari, E., Helmeczy, K., Stewart, S., and Kofalvi, S. A. 2000. Improved RNA extraction and one-tube RT-PCR assay for simultaneous detection of control plant RNA plus several viruses in plant extracts. J. Virol. Methods 90:37-49.

32. Nie, X., and Singh, R. P. 2002. A new approach for the simultaneous differentiation of biological and geographical strains of Potato virus $\mathrm{Y}$ by uniplex and multiplex RT-PCR. J. Virol. Methods 104:41-54.

33. Okuda, M., and Hanada, K. 2001. RT-PCR for detecting five distinct tospovirus species using degenerate primers and dsRNA template. J. Virol. Methods 96:149-156.

34. Rybicki, E. P., and Hughes, F. L. 1990. Detection and typing of maize streak virus and other distantly related geminiviruses of grasses by polymerase chain reaction amplification of a conserved viral sequence. $\mathrm{J}$. Gen. Virol. 71:2519-2526.

35. Saade, M., Aparicio, F., Sánchez-Navarro, J. A., Herranz, M. C., Myrta, A., Di Terlizzi, B., and Pallás, V. 2000. Simultaneous detection of the three ilarviruses affecting stone fruit trees by nonisotopic molecular hybridization and multiplex reverse-transcription polymerase chain reaction. Phytopathology 90:1330-1336.

36. Sherwood, J. L., Sanborn, M. R., Keyser, G. C., and Myers, L. D. 1989. Use of monoclonal antibodies in detection of Tomato spotted wilt virus. Phytopathology 79:61-64.

37. Taba, S., Naito, T., and Takaesu, K. 2000. Necrotic yellow disease of New Zealand spinach (Tetragonia expansa Murr.) caused by Watermelon silver mottle virus (WSMV). (Abstract in Japanese.) Jpn. J. Phytopathol. 66:146-147.

38. Takeuchi, S., Okuda, M., Hanada, K., Kawada, Y., and Kameya-Iwaki, M. 2001. Spotted wilt disease of cucumber (Cucumis sativus) caused by Melon yellow spot virus. (In Japanese with English summary.) Jpn. J. Phytopathol. 67:46-51.

39. Tanina, K., Inoue, K., Date, H., Hanada, K., Okuda, M., Nasu, H., and Kasuyama, S. 2000. Necrotic spot of cineraria and impatiens caused by Impatiens necrotic spot tospovirus. (Abstract in Japanese.) Jpn. J. Phytopathol. 66:147.

40. Tanina, K., Inoue, K., Date, H., Okuda, M., Hanada, K., Nasu, H., and Kasuyama, S. 2001. Necrotic spot disease of cineraria caused by $\mathrm{Im}$ patiens necrotic spot virus. (In Japanese with English summary.) Jpn. J. Phytopathol. 67:42-45.

41. Tsuda, S., Fujisawa, I., Hanada, K., Hidaka, S., Higo, K., Kameya-Iwaki, M., and Tomaru, K. 1994. Detection of Tomato spotted wilt virus S RNA in individual thrips by reverse transcription and polymerase chain reaction. Ann. Phytopathol. Soc. Jpn. 60:99-103.

42. Tsuda, S., Fujisawa, I., Ohnishi, J., Hosokawa, D., and Tomaru, K. 1996. Localization of Tomato spotted wilt tospovirus in larvae and pupae of the insect vector, Thrips setosus. Phytopathology 86:1199-1203.

43. Tsuda, S., Hanada, K., Fujisawa, I., Kameya-Iwaki, M., and Tomaru, K. 1994. The demonstration of strain-specific antigenic determinants on nucleocapsid of Tomato spotted wilt virus by monoclonal antibodies. Ann. Phytopathol. Soc. Jpn. 60:216-220.

44. Uematsu, S., Okuda, M., Ebihara, Y., Mihira, T., Hanada, K., Fukumoto, F., and Iwanami, T. 2003. Occurrence of yellow necrosis symptoms of some ornamental flowers and onion associated with Iris yellow spot virus. (Abstract in Japanese.) Jpn. J. Phytopathol. 69:46-47.

45. Williams, L. V., López Lambertini, P. M., Shohara, K., and Biderbost, E. B. 2001. Occurrence and geographical distribution of tospovirus species infecting tomato crops in Argentina. Plant Dis. 85:1227-1229. 